\section{Preliminary Laryngeal Examination During \\ Magnifying Upper Gastrointestinal Video \\ Endoscopy in Two Patients with Reflux Symptoms}

A 59-year-old man (with a 40-year-long history of smoking) and a 53-year-old woman were referred because of reflux symptoms, such as heartburn and regurgitation, associated with dysphonia, chronic throat clearing and globus pharyngeus. The man had undergone Billroth II gastrectomy 29 years previously, while the woman had a history of cholecystectomy 32 years previously.

Their symptoms prompted us to perform a preliminary evaluation of the larynx in both patients during a magnifying upper gastrointestinal endoscopy (using a Fuji EG-485ZH video endoscope). After local surface anesthesia with $0.4 \%$ benoxinate hydrochloride, and before introduction of the scope into the esophagus, careful inspection of the larynx with the video endoscope revealed vocal cord leukoplakia and signs of chronic laryngitis in both patients (Figure $\mathbf{1}$ and 2). Furthermore, in both patients, upper gastrointestinal endoscopy revealed signs of esophagitis, hiatus hernia, and a large amount of bile in the stomach. Subsequently, the ear, nose, and throat (ENT) specialist confirmed our preliminary laryngeal findings. After vocal cord decortications, histological examination revealed moderate epithelial dysplasia on the vocal cords in both patients. They were therefore treated with prokinetic and acid-suppressive drugs, and a ENT follow-up program was established.

On the basis of these cases, we recommend preliminary examination of the larynx during upper gastrointestinal video endoscopy in patients in whom a harmful biliary reflux extending as far as the larynx is suspected. Previous cholecystectomy or gastrectomy may constitute underlying conditions that predispose towards this type of reflux into the esophagus as far as the larynx; in general, the barrier function of the lower esophageal sphincter is defective [1-5]. A prolonged history of smoking, as in our male patient, reinforces the motive for exploring the larynx in these patients. Further studies

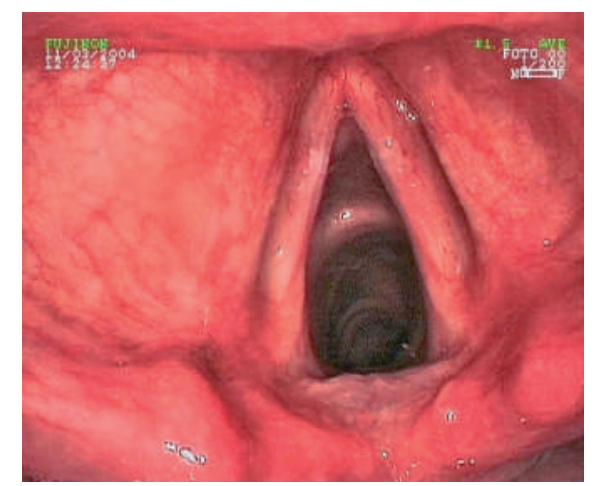

Figure 1 Laryngeal leukoplakia in a 59-yearold man as visualized during a routine upper gastrointestinal endoscopy, using a high resolution video endoscope preset to $1.5 \times$ magnification.

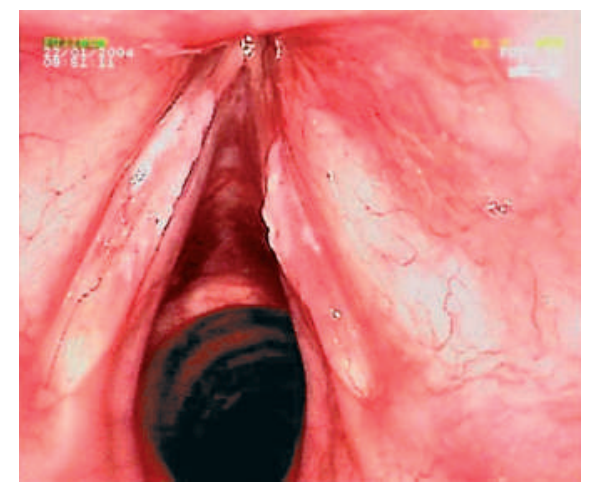

Figure 2 Nodules and leukoplakia of the posterior third of the true vocal cord in a 53year-old woman as visualized during upper gastrointestinal endoscopy, using a high resolution video endoscope preset to $2.0 \times \mathrm{mag}$ nification.

will be needed to investigate the potential of routine upper gastrointestinal video endoscopy for screening patients who may require evaluation by an ENT specialist.

\section{Videos}

Competing interests: None

online content including video sequences viewable at:

www.thieme-connect.de/ejournals/

abstract/endoscopy/doi/

10.1055/s-2006-925216
G. Cammarota ${ }^{1}$, S. Agostino ${ }^{2}$, M. Rigante'2, P. Cesaro'1, C. Parilla², R. La Mura', G. Gasbarrini' ${ }^{1}$ J. Galli ${ }^{2}$

${ }^{1}$ Departments of Internal Medicine and Gastroenterology, Catholic University of Medicine and Surgery, Rome, Italy

2 Department of Otorhinolaryngology, Catholic University of Medicine and Surgery, Rome, Italy

\section{References}

${ }^{1}$ Vaezi MF. Sensitivity and specificity of reflux-attributed laryngeal lesions: experimental and clinical evidence. Am J Med 2003; 115 (Suppl 3A): 97S - 104S

${ }^{2}$ Cianci R, Galli J, Agostino S et al. Gastric surgery as a long-term risk factor for malignant lesions of the larynx. Arch Surg 2003; 138: 751 - 754

${ }^{3}$ Cammarota G, Galli J, Cianci R et al. Association of laryngeal cancer with previous gastric resection. Ann Surg 2004; 240: 817-824

${ }^{4}$ Mearin F, De Ribot X, Balboa A et al. Duodenogastric bile reflux and gastrointestinal motility in pathogenesis of functional dyspepsia. Role of cholecystectomy. Dig Dis Sci 1995; 40: $1703-$ 1709

${ }^{5}$ Ma ZF, Wang ZY, Zhang J Ret al. Carcinogenic potential of duodenal reflux juice from patients with long-standing postgastrectomy. World J Gastroentrol 2001; 7: 376-380

\section{Corresponding Author}

\section{G. Cammarota, M.D.}

Istituto di Medicina Interna

Policlinico Universitario "A. Gemelli”

Largo A. Gemelli

00168 Roma

Italy

Fax: +39-06-35502775

E-mail: gcammarota@rm.unicatt.it 